\title{
Shark island pedicle flap for large reconstruction of the upper lip
}

\section{Leonardo Bugatti}

\author{
Dermatology Department, Carlo Urbani Hospital, Jesi (AN) Italy
}

Corresponding author: Dr. Leonardo Bugatti, E-mail: bugattiderma@gmail.com

Sir,

The principle of an ideal upper lip reconstruction include repair of all subunits disrupted by the lesion, restoration of dynamic motion, sensation, oral sphincter competence and minimization of distortion and disfigurement [1-3]. The "shark" island flap is optimized for reconstruction of large defects of the upper lip without significant muscle involvement in a single stage procedure.

Two cases are reported where the same procedure is used to remove a basal cell carcinoma involving part of the cutaneous upper lip. The skin around the lesion is outlined locating the incision in the sub-nasal fold, the lateral philtrum, the vermilion margin and the melolabial fold, comprising entirely the upper lip subunit. A V-flap with a shark-like shape is also outlined on the cheek lateral to the defect (Figs. la and 2a). Local anesthetic solution with a concentration of $2 \%$ mepivicaine + adrenaline 1:100.000 is injected into the dermis around the defect and the lateral donor site. The lesion is incised as planned and removed (Fig. lb). Deep incisions are made in the superior and inferior limbs of the flap, up to the sub-dermal plane, followed by medially adequate undermining of the surrounding skin. Once the flap is properly dissected, it is advanced to close as much defect area as possible with minimal deviation of the philtrum and anchored superiorly and inferiorly with subcutaneous stitches. As soon as the initial defect area has been covered, the rest of the secondary defect is closed by direct approximation of the free margins with a direct suture (Figs. 1c and 2c). Adequate follow-up time is given for complete and proper recovery (Figs. ld, 2c and 2d).

When the upper lip defect to cover is large, flaps may have the drawback of causing deformation on natural folds as well as distortion on the nostrils and the vermilion. In this case the subcutaneous island flap is a good option for upper lip restoration allowing: great skin mobility from the medial cheek, reconstruction of an entire lip sub-unit with cosmetically, functionally and topographically similar skin, lateral advancement of tissue without significant philtrum deformation or up-down-words pulling causing facial asymmetry. This technique is successful because the flap maintains vitality thanks to a wide subcutaneous pedicle and it naturally slides into the defect combining movements of advancement and rotation.

Optimal results in a single- staged procedure are obtained, allowing preservation of the cosmetic subunit of the

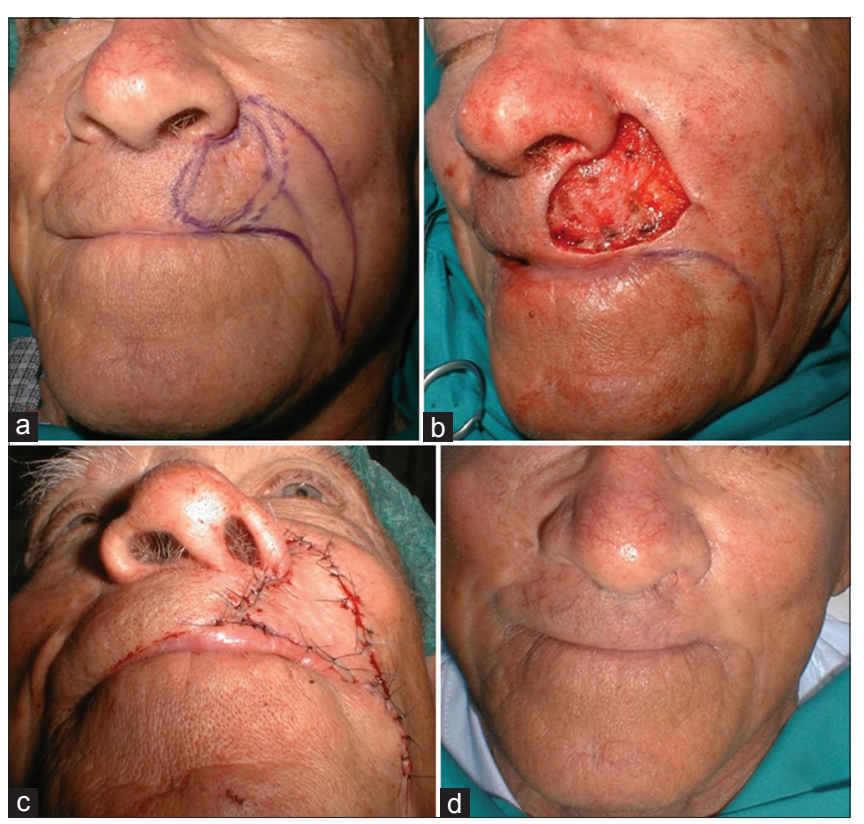

Figure 1: Case 1. (a) Pre-surgical planning of incisions. (b) Surgical defect. (c) Immediate post-operative picture (d) Six months follow-up picture.

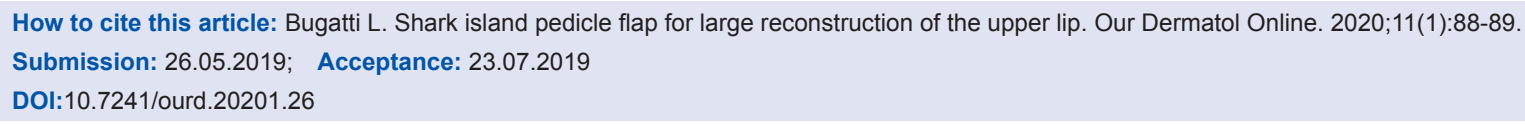



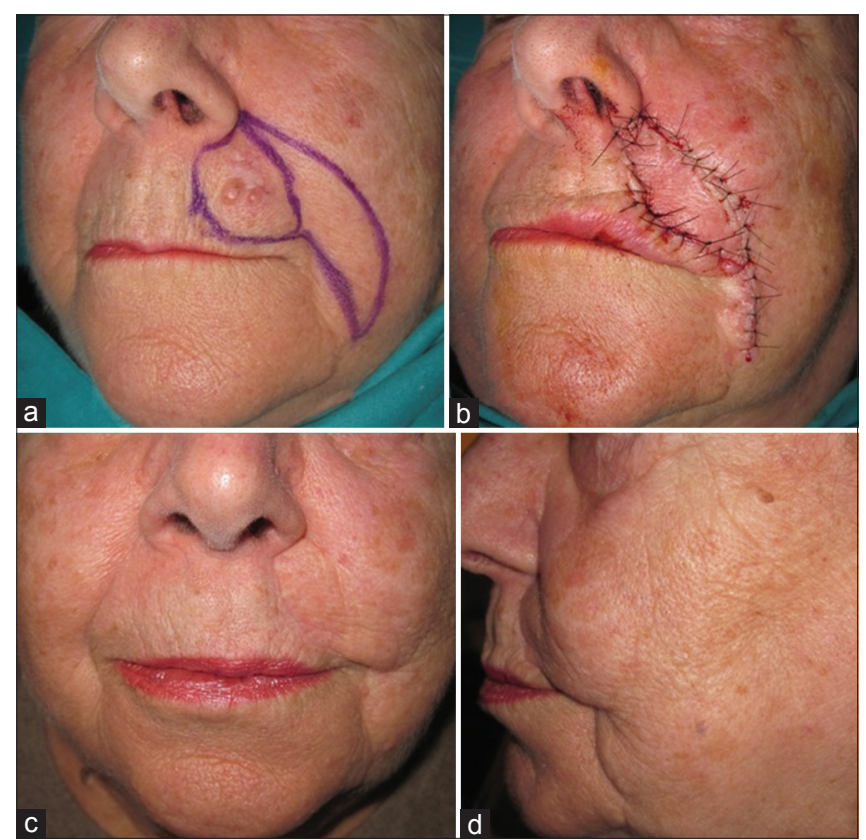

Figure 2: Case 2. (a) Pre-surgical planning of incisions. (b) Immediate post-operative picture (c-d) Nine months follow-up picture. upper lip with minimal postoperative distortion of the philtrum which is completely recovered within weeks.

\section{Consent}

The examination of the patient was conducted according to the Declaration of Helsinki principles.

\section{REFERENCES}

1. Martin TJ, Zhang Y, Rhee JS. Options for upper lip reconstruction: a survey-based analysis. Dermatol Surg. 2008;34:16-52.

2. Kaufman AJ. Repair of large surgical defect involving the upper lip and medial cheek. Dermatol Surg. 2000;26:699-81.

3. Fernandez-Casado A, Agustì T, Pujol RM. Reconstruction of defects in the paramedian upper lip. Dermatol Surg. 2009;35:1541-4.

Copyright by Leonardo Bugatti. This is an open-access article distributed under the terms of the Creative Commons Attribution License, which permits unrestricted use, distribution, and reproduction in any medium, provided the original author and source are credited.

Source of Support: Nil, Conflict of Interest: None declared. 